$\begin{array}{lllllll}\mathrm{R} & \mathrm{E} & \mathrm{S} & \mathrm{E} & \mathrm{N} & \mathrm{H} & \mathrm{A}\end{array}$

isto significa é que a problemática regional brasileira carece mais que nunca de um projeto nacional" (p.268).

Esta última constatação, da maior importância na discussão atual, é reforçada pela concepção do autor a respeito do papel que neste contexto de economia continental, heterogênea e desigual teriam as forças do mercado. Isto é realizado segundo o paralelo entre a situação vivida pela economia do país até os anos 80 , que tinha por base a integração do mercado interno nacional e os efeitos de sinergia promovidos por essa integração, "mesmo diante de um quadro de profunda desigualdade social", e a situação recente de total ausência de políticas. Continua o autor: "Largada ao mercado, sem políticas ativas, o que se vislumbra são iniciativas pontuais e isolacionistas que fraturam a nação e alicerçam o regionalismo ... O discurso em moda, ao contrário, vaticina um Estado submisso à lógica privada, que apenas alavanque as estratégias exitosas das grandes empresas e conceda às esferas subnacionais um papel progressivamente mais importante na atração de investimentos. Para um país com os níveis de desigualdade do Brasil pode-se imaginar o que isto significa" (p. 268-9).

Escrito em grande parte como tese em 1995, o livro, não obstante as transformações ocorridas, até mesmo com o agravamento da situação econômica do país e o comprometimento da estabilidade monetária, é de grande atualidade no que se refere sobretudo aos "dilemas da nova problemática regional”. Ao lado das sugestões feitas por Luciano Coutinho, na "Apresentação" do livro, para incluir análise a respeito do impacto regional decorrente do surto de ampliação do consumo que se seguiu à fase imediata da estabilização, ou da reativação de alguns segmentos produtivos, seria relevante considerar, em fase mais recente, também da perspectiva espacial, o impacto da crescente instabilidade vivida pelo país, associada e decorrente dos equívocos e do esgotamento da política de estabilização, do crescente endividamento do Estado e da sua, também, crescente incapacidade de gestão de políticas industriais, agrícolas, regionais, de infra-estrutura e de exportação, entre outras.

Leonardo Guimarães Neto é doutor em Economia e professor do Mestrado e do Departamento de Economia da Universidade Federal da Paraíba.

\section{PLANEJAMENTO URBANO NOS ANOS 90: NEGOCIAÇÕES ENTRE AS ESFERAS PÚBLICA E PRIVADA}

Ana Cláudia Miranda Dantas

Dissertação de Mestrado, Instituto de Pesquisa e Planejamento Urbano e Regional da Universidade Federal do Rio de Janeiro, 1997.

Adauto Lúcio Cardoso

Os chamados "novos instrumentos" ocuparam um espaço importante no debate acadêmico, técnico e político da área do planejamento e da política urbana, desde o início dos anos 80, quando foi divulgado o anteprojeto de Lei Nacional de Desenvolvimento Urbano, até meados dos anos 90, quando se elaboram planos diretores municipais para as grandes cidades brasileiras. É no contexto desse debate que se insere a dissertação de mestrado de Ana Cláudia Miranda Dantas.

O trabalho de Ana Cláudia tem como base factual um levantamento exaustivo e primoroso da forma como 34 municípios, escolhidos entre as cinqüenta cidades mais populosas do país, definiram, em suas leis orgânicas e planos diretores, um conjunto específico de novos instrumentos, a saber: o solo criado, a transferência do direito de construir, as operações interligadas, as operações urbanas, o consórcio imobiliário e a urbanização e reurbanização consorciadas. O que distingue esses instrumentos e os faz interessantes como objeto de pesquisa é que se tratam de novas formas de relacionamento entre as esferas pública e privada, envolvendo, entre outras coisas, repasses de recursos da esfera privada ao poder público ou redefinição de competências para intervir sobre o urbano.

O levantamento é detalhado e identifica-se pela análise da legislação, a denominação, a definição, os objetivos, as condições de aplicação, as finalidades de utilização dos recursos, a responsabilidade pela implementação e os critérios ou limites para a aplicação dos instrumentos. A pesquisa sistemática e a análise comparativa permitem, já como uma primeira e importante conclusão desse trabalho, mostrar como, na falta de uma regulamentação federal, ocorre uma certa confusão conceitual, com vários municípios utilizando instrumentos de denominação semelhantes mas com 
objetivos e formas de aplicação completamente diversos, a ponto de não se distinguir, por exemplo, em alguns casos, diferenças significativas entre o solo criado e as operaçôes interligadas.

A abrangência, o detalhamento e a qualidade do trabalho de sistematização e comparação das legislações, em si, já recomendam esse trabalho pela sua importância para a discussão sobre os novos formatos $\mathrm{da}$ legislação urbanística e sobre a regulamentação dos instrumentos de política urbana em âmbito federal, já que, até hoje, não temos uma lei de desenvolvimento urbano aprovada. Trata-se também de uma contribuição extremamente relevante para as atividades acadêmicas, servindo como texto de apoio para debates em sala de aula ou como fonte de dados para pesquisas discentes e docentes. Como uma contribuição complementar nessa direção, a dissertação apresenta um levantamento minucioso sobre a origem dos instrumentos e sobre os primeiros debates travados no Brasil, na década de 1970, permitindo, assim, a construção de uma perspectiva histórica que alimenta, de forma bastante profícua, o debate sobre os impasses da contemporaneidade.

Desde meados da década de 1960, o planejamento urbano vinha sendo objeto de críticas contumazes, que contestavam tanto os padrões de urbanidade gerados pelas soluçôes espaciais inspiradas no modelo modernista, quanto a capacidade dos planos abrangentes e de longo prazo responderem efetivamente às necessidades de ordenação do crescimento urbano. Nesse sentido, os instrumentos que, tradicionalmente, eram usados para construir o chamado "equilíbrio urbanístico", como o zoneamento, passam a ser vistos como elitistas ou ineficazes. No âmbito dessas críticas, tornava-se necessário, ainda, criar novas formas de intervenção que permitissem ao poder público controlar com maior eficácia a especulação fundiária e reverter, ao menos em parte, a apropriação, pelos capitais privados, dos investimentos públicos em infra-estrutura e serviços urbanos. ${ }^{1}$

Como mostra o trabalho de Ana Cláudia, esse debate emerge com muita força, principalmente na Europa, nos anos 70 , chegando, em suas propostas mais

10 debate sobre a apropriação privada de investimentos públicos acompanha a história do urbanismo, já estando presente desde as suas origens, nas décadas de 1910 e 1920 . Esse debate se revigora nos anos 70 , sendo relevante a contribuição das análises da economia espacial e da crítica marxista. radicais, a estabelecer a municipalização do solo urbano ou a separação entre direito de propriedade e direito de construir. O solo criado surge como proposta intermediária, sendo definido como um instrumento que estabelece um índice único, em geral igual a um, acima do qual o poder público pode "vender" índices adicionais ("solos" criados), até um determinado limite, estabelecido em relação às possibilidades locais de adensamento. No entanto, não é apenas a reapropriação dos investimentos públicos que justifica essa proposição. Um outro enfoque é a idéia de que esse instrumento permite, de forma mais ágil e flexível, agir sobre o mercado, criando o "equilíbrio urbanístico". É essa concepção que será trazida ao debate brasileiro e que será consagrada na famosa Carta do Embu, em que vários juristas de renome formam um consenso sobre a importância da adoção desse instrumento para melhorar a capacidade de ação municipal na regulamentação do uso do solo urbano.

O trabalho de Ana Cláudia mostra, ainda, que essa dupla definição do instrumento - de ampliação da eficácia do investimento público e de equilíbrio urbanístico - ganha outros contornos quando do debate pré-constitucional. Influenciado pelo impacto causado pela utilização das Operaçôes Interligadas como instrumento de financiamento da política habitacional do Governo de Luiza Erundina, do Partido dos Trabalhadores, na Prefeitura de São Paulo, o solo criado passa a ser compreendido, no âmbito das propostas da Reforma Urbana, como um instrumento redistributivo. Ou seja, trata-se de uma apropriação, pelo poder público, de parcela da valorização imobiliária originária dos investimentos públicos na cidade, para investimento específico em atendimento a famílias de baixa renda, nas áreas de habitação e infra-estrutura. Esse entendimento múltiplo sobre as definições e os objetivos do instrumento irá reaparecer, mais tarde, por meio das confusões conceituais anteriormente apontadas.

$\mathrm{O}$ contexto das mudanças que acontecem no final dos anos 80 e início dos 90 irá emprestar outras características a esse debate. Como é identificado pelo texto, os impactos da globalização e da reestruturação produtiva sobre o governo das cidades irá trazer para o centro das discussóes da área novas concepções, que parecem se constituir como um novo padrão de gestão, caracterizado por David Harvey como "empreendedo- 
rismo urbano". ${ }^{2}$ No âmbito dessas propostas, privilegiase a constituição de um novo formato para a ação pública, não apenas por meio da liberação de entraves regulatórios sobre a ação dos capitais imobiliários, como ocorreu na Inglaterra da época Thatcher, mas também por meio da participação da iniciativa privada, em "parceria" com a administração local, no desenvolvimento de políticas que aumentem a competitividade urbana.

Modifica-se, então, uma vez mais, os termos da discussão sobre os instrumentos, sendo estes enfocados como potencializadores ou facilitadores da flexibilização e das parcerias. É nesse sentido que a dissertação conclui com uma proposta extremamente interessante e audaciosa: estar-se-ia constituindo um novo padrão de planejamento das cidades, denominado de "planejamento por negociaçōes", definido como "um planejamento comprometido com a negociação e com o estabelecimento de parcerias entre atores públicos e privados" e caracterizado por "operações pontuais, e de contratos de diferentes tipos, a serem negociados, caso a caso, com diversos atores envolvidos ... [com] a função de atender a situações probabilísticas, casuais e inscritas numa infinidade de especificidades locais" (p.148).

Dentre os instrumentos analisados, a autora ressalta que o solo criado e a transferência do direito de construir aproximam-se mais dos princípios e características do planejamento regulatório, enquanto as operaçôes urbanas, operações interligadas, consórcio imobiliário e a urbanização e reurbanização consorciadas seriam mais claramente identificadas com o modelo do planejamento por negociaçōes.

O texto conclui sem uma avaliação clara das positividades ou dos problemas inscritos nessa nova "tendência" apontada. Por um lado, parece que a autora tem uma certa simpatia pela possibilidade aberta pelos novos instrumentos para dar conta das especificidades locais e da imprevisibilidade e da incerteza que seriam constitutivas da produção dos ambientes urbanos. Por outro, também aparece com destaque a incapacidade desses instrumentos em assumir claramente um papel redistributivo, o que é visto como um aspecto negativo. O que talvez pudesse ser acrescentado, nesse caminho, como uma questão adicional para essa avaliação,

2 Conforme Harvey, D. "Do gerenciamento ao empresariamento: a transformação da administração urbana no capitalismo tardio". Espaço \& Debates, v.16, n.39, 1996. é o problema do rompimento do padrão universalista de intervenção sobre o urbano que marca o enfoque regulatório clássico. Os novos instrumentos, em particular aqueles que caracterizam mais diretamente o planejamento por negociaçôes, ao se legitimarem com base no discurso do aumento da competitividade urbana e da eficiência do poder público, deixam de lado o princípio da norma como uma regulação que se impõe, de forma universal e impessoal, sobre a sociedade. Ao acentuar o caso a caso, o específico e o contrato, caem por terra os princípios da eqüidade, da impessoalidade e do universalismo, valores que sempre legitimaram a intervenção pública. A norma, tornada flexível e negociável, passa a permitir uma distinção que se torna constitutiva da nova relação dos cidadãos com o urbano, de ora em diante: ela vale para todos, menos para alguns, para os que podem negociar ou ser parceiros do poder público. Será possível construirmos cidades democráticas e socialmente justas, com base nesses valores? A leitura desse instigante trabalho nos ajuda, senão a responder, pelo menos a ter bases sólidas para que se possa discutir essa questão.

Adauto Lúcio Cardoso é professor do Instituto de Pesquisa e Planejamento Urbano e Regional da Universidade Federal do Rio de Janeiro.

\section{CONFRONTOS E CONTRASTES REGIONAIS DA CIÊNCIA E TECNOLOGIA NO BRASIL}

Fernando Antônio de Barros

Brasília: Paralelo 15/Universidade de Brasília, 1999.

\section{Brasilmar Ferreira Nunes}

O estudo de Fernando Antônio Barros tem qualidades evidentes. A primeira delas é a oportunidade de retomar uma discussão já clássica dentro das ciências sociais no Brasil, qual seja, a questão regional. Uma temática que teve o seu auge nos anos 60 e que culminou com a institucionalização de instâncias específicas dentro do aparelho de Estado com funçôes definidas em decorrência das nossas gritantes desigualdades regionais. Um tema que apesar de ainda ser facilmente constatado nas estatísticas oficiais passou para segundo plano nos estudos acadêmicos talvez por uma certa 